\title{
Diagnóstico da Infecção do Trato Urinário e indicação de Antibioticoterapia através
}

\section{da Medicina Laboratorial}

\author{
Diagnosis of Urinary Tract Infection and indication of Antibiotic Therapy through Laboratory \\ Medicine \\ Diagnosis of Urinary Tract Infection and indication of Antibiotic Therapy though Laboratory \\ Medicine
}

Recebido: 27/06/2021 | Revisado: 04/07/2021 | Aceito: 13/07/2021 | Publicado: 23/07/2021

\author{
Bruno Ricardo Santana dos Santos \\ ORCID: https://orcid.org/0000-0003-2259-1457 \\ Faculdade Nobre de Feira de Santana, Brasil \\ E-mail: brunoricsan@gmail.com \\ Francis Claudia Souza Porto Santos \\ ORCID: https://orcid.org/0000-0003-4334-0980 \\ Faculdade Nobre de Feira de Santana, Brasil \\ E-mail: francisporto@hormail.com \\ Luana Simões Bezerra \\ ORCID: https://orcid.org/0000-0001-6096-5654 \\ Faculdade Nobre de Feira de Feira de Santana, Brasil \\ E-mail: biomedsimoes@gmail.com
}

\begin{abstract}
Resumo
A pesquisa objetiva-se no diagnóstico da Infecção do Trato Urinário (ITU) de modo a correlacionar o sumário de urina e a urocultura com antibiograma apresentados em artigos originais, permitindo uma análise farmacoterápica. Decorre de um estudo de acordo com as diretrizes do protocolo PRISMA, realizado no período que compreende julho de 2015 a setembro de 2016, trata-se de uma revisão bibliográfica de natureza qualitativa e quantitativa. Em conformidade, os resultados apresentaram como principal agente etiológico a bactéria Escherichia coli, obtendo uma média de 57,5\% das infecções confirmadas, com resistência ao antibiótico ampicilina em $61 \%$ dos antibiogramas realizados, com maior prevalência no sexo feminino, considerando grupos mais suscetíveis as gestantes e os idosos. Contudo, o sumário de urina é considerado um exame de baixo custo e de primeira linha acessível na investigação dos casos suspeito de ITU, no entanto é indispensável à realização da urocultura com antibiogrma mediante a resistência que os uropatógenos vêm desenvolvendo aos antimicrobianos (antibióticos), uma vez que a urocultura possibilita a identificação do microorganismo responsável pela infecção, e o antibiograma a seleção dos antimicrobianos que a bactéria não apresenta resistência, possibilitando adotar uma melhor conduta terapêutica.
\end{abstract}

Palavras-chave: Infecções urinárias; Bacteriologia; Testes de sensibilidade microbiana.

\begin{abstract}
The objective in the diagnosis of Urinary Tract Infection Research (ITU) in order to correlate the urinalysis and urine culture with antibiogram presented in original papers, allowing pharmacotherapy analysis. Results from a study in accordance with the guidelines of the PRISMA protocol, performed in the period comprising July 2015 to September 2016, it is a literature review of qualitative and quantitative nature. Accordingly, the results showed the main etiological agent Escherichia coli, obtaining an average of $57.5 \%$ of confirmed infections with resistance to the antibiotic ampicillin in $61 \%$ of antibiograms performed, with a higher prevalence in females, considering most susceptible groups pregnant women and the elderly. However, the urinalysis is considered an examination low cost and first line available in the investigation of suspected cases of UTI, however it is essential to perform the urine culture with antibiogrma by the resistance that uropathogens have developed antimicrobial (antibiotic) once the urine culture enables identification of the microorganism causing the infection and the antimicrobial susceptibility testing the selection of the bacteria has no resistance, enabling to adopt a best treatment.
\end{abstract}

Keywords: Urinary infections; Bacteriology; Microbial sensitivity tests.

\section{Resumen}

La investigación tiene como objetivo el diagnóstico de Infección del Tracto Urinario (ITU) con el fin de correlacionar el resumen de urocultivo y urocultivo con el antibiograma presentado en artículos originales, permitiendo un análisis farmacoterapéutico. Es el resultado de un estudio de acuerdo con las directrices del protocolo PRISMA, realizado en 
el período de julio de 2015 a septiembre de 2016, se trata de una revisión bibliográfica de carácter cualitativo y cuantitativo. Así, los resultados mostraron a la bacteria Escherichia coli como principal agente etiológico, obteniendo un promedio de 57,5\% de las infecciones confirmadas, con resistencia al antibiótico ampicilina en el $61 \%$ de los antibiogramas realizados, con mayor prevalencia en las mujeres, considerando los grupos más susceptibles de gestación. mujeres y ancianos. Sin embargo, el resumen de orina se considera una prueba de primera línea accesible y de bajo costo en la investigación de casos sospechosos de ITU, sin embargo es fundamental realizar un urocultivo con antibiograma debido a la resistencia que los uropatógenos han ido desarrollando a los antimicrobianos (antibióticos), una vez que el urocultivo permite la identificación del microorganismo responsable de la infección, y el antibiograma la selección de antimicrobianos que la bacteria no presenta resistencia, lo que permite adoptar un mejor abordaje terapéutico.

Palabras clave: Infecciones urinarias; Bacteriología; Pruebas de sensibilidad microbiana.

\section{Introduçãa}

A infecção no trato urinário (ITU) se dá através da instalação de microrganismos patogênicos como Eschrichia coli, espécies de Enterobacter, Citrobacter, Klebsiella e Proteus por via ascendente ou via hematogênica e delimitada pelo sítio anatômico, a cistite bacteriana ocorre na bexiga, à uretrite nos ureteres e a pielonefrite nos rins (Strasinger, 2009). A ITU é mais frequentes em pacientes do sexo feminino em relação ao masculino, a justificativa mais aceita é o pelo tamanho da uretra que em pacientes do sexo feminino possui $5 \mathrm{~cm}$ enquanto no masculino aproximadamente $20 \mathrm{~cm}$, outros fatores relacionados é a proximidade do ânus a uretra (Filho, 2010); a ambiente úmido nas mulheres e a atividade antimicrobiana do líquido prostático nos homens (Dallacorte, 2007).

Os fatores que predispõe a ITU em pacientes do sexo feminino são mais de quatro relações sexuais mensais, espermicidas, anticoncepcional oral, disfunção miccional e o uso freqüente de antibacterianos que altera a microbiota vaginal normal composta de Lactobacillus acidóphilus, possibilitando a colonização por Escherichia coli, predispondo às infecções através da aderência destas bactérias ás células uroepiteliais (Korb, 2013).

Os sinais clínicos apresentados na cistite e uretrite bacteriana são desejo forte e persistente em urinar, disúria, pequenas e frequentes micções, hematúria, urina turva e com odor, desconforto na região pélvica, dor supra púbica e febre baixa. A pielonefrite é marcada pela tríade dor na região lombar, seguida de calafrios e febre alta, podendo ainda ocorrer náuseas e vômitos no quadro clínico do paciente (Corrêa, 2010).

Os sintomas pertinentes à infecção do trato urinário vêm sendo relacionado também com fatores ocupacionais no que afetam hábitos de hidratação, principalmente em pacientes do sexo feminino. Fisiologicamente permanecer hidratado significa consumir água suficiente durante todo o dia e esvaziar a bexiga sempre que necessário. A hidratação é influenciada por fatores fisiológicos, dietéticos, metabólicos, ambientais e até mesmo comportamentais. Nos últimos anos em acedência observou-se a relação da hidratação a diversos problemas de saúde, onde os sintomas de infecção do trato urinário têm sido correlacionados à diminuição da ingestão de água e a comportamentos considerados insalubres como exemplo na utilização de banheiros (Nerbass et al., 2021).

Com a finalidade de confirmar um quadro de ITU o primeiro exame solicitado é o sumário de urina podendo esse apontar uma bacteriúria aumentada, hematúria e piúria (LOPES, 2005). O exame é dividido em três etapas que compreende a análise física com o registro do volume, cor, aspecto, gravidade específica e $\mathrm{pH}$, análise química onde se observa proteínas, glicose, cetona, ácido ascórbico, bilirrubina, urobilinogênio, sangue e nitrito e por último a sedimentoscopia onde é constatado e quantificado a presença de leucócitos, bactérias, cilindros, cristais, células epiteliais, hemácias, cristais e muco (Alves, 2011).

No entanto o sumário de urina não é padrão ouro para o diagnóstico e conduta terapêutica da ITU uma vez que é na urocultura que se identifica o agente a partir do crescimento das cepas bacterianas de no mínimo 100 mil unidades formadora de colônia (UFC) com o auxílio do antibiograma delimita-se os antibióticos que a bactéria apresenta sensibilidade ou 
resistência permitindo ao médico prescrever o antimicrobiano e a sua dosagem mais adequada a clínica do paciente (Guidoni, 2001).

Sendo a Cistite e a Pielonefrite doenças sintomáticas, onde se observa reincidências de acordo com as resistências bacterianas apresentadas pelo uso inadequado de antibiótico o presente trabalho tem por objetivo correlacionar o sumário de urina de pacientes com ITU, aos principais dados publicados de antibiogramas e uroculturas através de artigos originais, de modo a possibilitar também uma análise farmacoterápica.

\section{Metodologia}

Trata-se de uma revisão sistemática de natureza descritiva e explicativa com abordagem qualitativa e quantitativa realizada entre julho de 2015 a setembro de 2016 de acordo com as diretrizes do protocolo PRISMA (Galvão, 2015). Foram utilizados os descritores, "ITU" and "Cistite" and "Pielonefrite" and "Resistência Bacteriana" and "Urocultura", através da palavra-chave "Infecção no Trato Urinário" nas bases de dados: Scielo, LILACS e Medline.

“A pesquisa quantitativa aplica-se à dimensão mensurável da realidade origina-se na revisão newtoniana dos fenômenos e transita com eficácia na horizontalidade dos extratos mais densos e materiais da realidade. Seus resultados auxiliam o planejamento de ações coletivas e produz resultados passíveis de generalização, principalmente quando as populações pesquisadas representam com fidelidade o coletivo" (BIGNARDI, 2001).

E também qualitativa uma vez que a mesma detém um propósito de um estudo específico que deriva de um quadro teórico traçado de acordo ao objetivo da pesquisa. Com esses objetivos em mente, os observadores começam a coletar dados, sempre buscando manter uma perspectiva holística sem se desviar muito de seu foco de interesse. Por isso, localiza-se observações que são particularmente úteis em certos aspectos, para que não obtenha um monte de informações irrelevantes, nem obtenha alguns dados, para que possa fazer uma análise mais completa do problema. (Ludke, 1986).

Os critérios de elegibilidade adotados foram: a) veículo de publicação: periódicos indexados; b) período de publicação: 2006-2020; c) idiomas: português, Inglês ou espanhol; d) modalidade da produção: artigos originais; e) qualidade metodológica: pesquisas de campo que possuam como tema central "Infecção no Trato Urinário" e apontem o diagnóstico através do sumário de urina e/ou urocultura com antibiograma, assim como resistência bacteriana aos farmacoterápicos e consequentemente permitam uma avaliação epidemiológica. Com tais pressupostos os artigos pesquisados devem definir a quantidade de participantes assim como tipo de estudo, procedimentos e instrumento.

Como exemplo de descrição ampla de uma estratégia deve-se acessar o site http://www.scielo.org/php/index.php selecionar o modo "integrado" e no campo identificado como "Entre com uma ou mais palavras" deve-se inserir "Infecção no Trato Urinário" e clicar em pesquisar.

A Técnica de análise de dados compreendeu na análise de pesquisas originais que abordam a Infecção bacteriana no Trato Urinário (Cistite ou Pielonefrite), de acordo com padrões socioeconômicos apresentados nas pesquisas, as quais permitiram correlacionar o sumário de urina com a urocultura e antibiograma, evidenciando a importância do diagnóstico correto, apresentando os dados em três figuras permitindo uma melhora visualização e compreensão dos resultados.

\section{Resultados e Discussão}

No levantamento realizado foram identificados 150 artigos que apresentam como temática "Infecção do Trato Urinário" dos quais 20 estão de acordo o objetivo desse artigo e apenas 9 respondem aos critérios de inclusão, sendo incluído mais 3 artigos, o primeiro ressalta as normativas do protocolo PRISMA do inglês Preferred Reporting Items for Systematic 
Reviews and Meta-Analyses (Principais itens para relatar Revisões sistemáticas e Meta-análises) o segundo e o terceiro aborda Análise de Dados na Pesquisa Científica, incluindo também 2 capítulo de livro.

Guerra (2012) realizou um estudo analítico, prospectivo, do tipo transversal, que envolveu 164 gestantes admitidas na enfermaria de Gestão de Alto Risco do Instituto de Medicina Integral Professor Figueira (IMIP), localizado em Recife no estado de Pernambuco, Brasil, no período de janeiro a junho de 2011, o sumário de urina foi realizado de forma automatizada pelo aparelho Uriscan Pró II e a urocultura pelo laboratório central de microbiologia do IMP, colheu-se para o exame o jato intermediário da primeira urina do dia, foram considerados dois critérios de diagnóstico para posterior correlação com urocultura para análise dos resultados, o primeiro considerou diagnóstico de ITU pela presença de mais que quatro piócitos por campo e o segundo considerou a presença de piócitos e nitritos a bacteriúria.

De tal modo observa-se que o estudo de Guerra (2012) teve como objetivo validar o sumário de urina como método de diagnóstico para ITU, para isso considerou-se os critérios acima relatados correlacionando-os com a urocultura. Ao considerar a presença de mais de quatro piócitos por campo o sumário de urina seria sugestivo de ITU em 72 pacientes, no entanto desses apenas 20 pacientes apresentaram urocultura positiva, reproduzindo um percentual de $72,2 \%$ de erro diagnóstico, ainda em relação ao primeiro critério observou-se que 92 pacientes apresentaram piócitos normais dos quais 12 tiveram urocultura positiva para algum microorganismo. No segundo critério considerando o nitrito positivo associado à bacteriúria o sumário de urina foi sugestivo para ITU em 6 pacientes dos quais 4 apresentaram urocultura positiva obtendo um percentual de erro de 33,3\%. Ainda em relação ao segundo critério 158 pacientes apresentaram nitrito negativo e piócitos normais, no entanto a urocultura foi positiva em 28 desses pacientes.

O sumário de urina apresenta importantes dados a ser utilizado como primeira ferramenta no auxilio ao diagnóstico de ITU. Em alguns setores de saúde a urocultura com antibiograma não é disponibilizada e mesmo quando é realizado o tempo mínimo para a liberação do laudo é de 48 horas, por isso procura-se estabelecer critérios para utilizar o sumário de urina como ferramenta de diagnóstico inicial. Ao considerar como critério diagnóstico somente a presença de mais do que quatro piócitos por campo a margem de erro no diagnóstico aumenta, uma vez que a presença de leucócitos na urina sempre estará presente em todo processo inflamatório nas vias urinas e não apenas em ITU, ao considerar o nitrito positivo associado à bacteriúria a margem de erro diminui o que pode ser justificado, ao nos alimentarmos de leguminosas ou de herbívoros que se alimentaram de leguminosas, ingerimos nitrato. Algumas espécie de microorganismos absorve o nitrogênio $\left(\mathrm{N}_{2}\right)$ da atmosfera e fixa nas raízes de leguminosas, várias bactérias assim como cianobactérias reduzem o nitrogênio em amônia e essa em nitrato $\mathrm{NO}^{-2}$ permitindo a sua absorção pelo organismo, sendo o nitrato totalmente eliminado pela urina, quando presentes no trato urinário algumas bactérias que causam ITU como Escherichia coli, espécies de Enterobacter, Citrobacter, Klebsiella e Proteus por um meio de um método denominado nitritificação reduzem o Nitrato urinário $\left(\mathrm{NO}^{3-}\right)$ na espécie química tóxica Nitrito $\left(\mathrm{NO}^{2-}\right)$, o nitrito reage com o ácido p-arsilico originando um composto diazônio, que associado a quinolona produz a cor roza na fita reagente. A sedimentoscopia não pode ser excluída do sumário de urina, já que algumas bactérias não reduzem o nitrato urinário em nitrito e a urocultura não pode ser excluída do diagnóstico de ITU posto que para que o sumário de urina seja sugestivo de ITU é necessário a presença de nitratos no fluído corporal - urina e bactérias suficientes capazes de realizar a conversão de nitratos em nitritos, por isso a primeira coleta do dia é mais indicada pois possibilita uma maior presença de nitritos após a urina permanecer cerca de 4 horas na bexiga evitando resultados falsos negativos (Lehninger, 2006).

O estudo de Coelho (2008) foi realizado a partir de registros secundários das infecções do trato urinário em gestantes ocorridas no Ambulatório Materno Infantil (AMI) no período 01/01/2005 a 31/12/2005, considerou-se como ITU todas gestantes que apresentaram no sumário de urina presença de leucócitos, células epiteliais, nitrito e bacteriúria, indepedente da realização da urocultura. Entre o período citado foram atendidas 218 gestantes, no entanto, apenas 192 continuaram realizando o pré-natal, das quais 70 apresentaram alterações significativas do sumário de urina ou sintomatologia pertinente a ITU. 
Das 70 pacientes que apresentaram clínica para ITU na pesquisa de (Coelho, 2005) em 9 pacientes não foram realizados exames laboratoriais, $28(40 \%)$ apresentaram bacteriúria discreta, $5(7,14 \%)$ bacteriúria moderada, $11(15,71 \%)$ bacteriúria aumentada, 17 (24,9\%) não possuíam dados registrados no prontuários ou analisados mesmo sendo diagnosticado laboratorialmente. No sumário de urina foram encontrado de 1-250 leucócitos por campo, a hematúria esteve presente em 10 $(16,4 \%)$ dos casos descritos assim como: células epiteliais 14 (22,95\%), nitrito $6(10 \%)$. A urocultura foi apenas realizada em $28(40 \%)$ dos pacientes que apresentaram clínica para ITU.

Coelho (2008) reconhece que o diagnóstico da ITU exige a conjugação de dados clínicos e laboratoriais, no entanto o estudo demonstrou que dos 70 pacientes que apresentaram sintomatologia clínica para ITU 61 realizaram sumário de urina e somente 28 realizaram urocultura com antibiograma, concluindo que em $42(60 \%)$ dos casos foram realizados prescrição inadequada de antibiótico contribuindo consequentemente para resistência bacteriana, uma vez que somente a urocultura identifica a bactéria presente na ITU e o antibiograma define os antibióticos que a mesma apresenta sensibilidade e resistência.

Os estudos relacionados abaixo tratam-se de pesquisas de campo que tiveram como tema a Infecção do Trato Urinário e abordaram a Urocultura com Antibiograma como diagnóstico de ITU. Foram realizadas entre 2007 e 2011 nos conseguintes estados: Espírito Santo, Paraná, Maranhão, Rio Grande do Sul e Santa Catarina.

Tabela 1: Resultado das uroculturas de estudos originais publicados entre 2007 e 2013.

\begin{tabular}{|c|c|c|c|c|}
\hline \multicolumn{5}{|c|}{ UROCULTURA } \\
\hline Estudo & Ano & Local & N/T & $\%$ \\
\hline \multicolumn{5}{|c|}{ E. coli } \\
\hline FILHO & 2013 & $\begin{array}{c}\text { HSCMV } \\
\text { Vitória - ES }\end{array}$ & $409 / 585$ & 69,9 \\
\hline KORB & 2013 & Fazendo Rio Grande - PR & $240 / 265$ & 91 \\
\hline SANTANA & 2012 & $\begin{array}{l}\text { Laboratório privado } \\
\text { São Luís - MA }\end{array}$ & $258 / 565$ & 45,7 \\
\hline MARTINI & 2011 & Santa Maria - RS & $2.358 / 6.190$ & 38,1 \\
\hline HORNER & 2008 & $\begin{array}{c}\text { HUSM } \\
\text { Santa Maria-RS }\end{array}$ & $8 / 17$ & 47,2 \\
\hline HORNER & 2008 & $\begin{array}{c}\text { Comunidade } \\
\text { Santa Maria - RS }\end{array}$ & $6 / 10$ & 60 \\
\hline COELHO & 2008 & $\begin{array}{c}\text { AMI } \\
\text { Tubarão - SC }\end{array}$ & $5 / 11$ & 45,45 \\
\hline DALLACORTE & 2007 & $\begin{array}{l}\text { UPHSL (PUCRS) } \\
\text { Ipiranga - RS }\end{array}$ & $20 / 32$ & 62,5 \\
\hline MÉDIA & - & - & - & 57,5 \\
\hline \multicolumn{5}{|c|}{ Proteus spp } \\
\hline FILHO & 2013 & $\begin{array}{c}\text { HSCMV } \\
\text { Vitória - ES }\end{array}$ & $18 / 585$ & 3,1 \\
\hline KORB & 2013 & Fazendo Rio Grande - PR & $12 / 265$ & 4,5 \\
\hline MARTINI & 2011 & Santa Maria - RS & $223 / 6.190$ & 3,6 \\
\hline COELHO & 2008 & $\begin{array}{c}\text { AMI } \\
\text { Tubarão-SC }\end{array}$ & $1 / 11$ & 9.09 \\
\hline DALLACORTE & 2007 & $\begin{array}{c}\text { UPHSL (PUCRS) } \\
\text { Ipiranga - RS }\end{array}$ & $1 / 32$ & 3,1 \\
\hline MÉDIA & - & - & - & 4,7 \\
\hline \multicolumn{5}{|c|}{ Klebsiella spp } \\
\hline FILHO & 2013 & $\begin{array}{c}\text { HSCMV } \\
\text { Vitória - ES }\end{array}$ & $35 / 585$ & 6 \\
\hline
\end{tabular}


Research, Society and Development, v. 10, n. 9, e17310917599, 2021

(CC BY 4.0) | ISSN 2525-3409 | DOI: http://dx.doi.org/10.33448/rsd-v10i9.17599

\begin{tabular}{|c|c|c|c|c|}
\hline KORB & 2013 & Fazendo Rio Grande - PR & $2 / 265$ & 0,75 \\
\hline SANTANA & 2012 & $\begin{array}{c}\text { Laboratório privado } \\
\text { São Luís - MA }\end{array}$ & $146 / 565$ & 25,8 \\
\hline MARTINI & 2011 & Santa Maria - RS & $451 / 6.190$ & 7,3 \\
\hline HORNER & 2008 & $\begin{array}{c}\text { HUSM } \\
\text { Santa Maria - RS }\end{array}$ & $2 / 17$ & 11,7 \\
\hline MÉDIA & - & - & - & 10,3 \\
\hline \multicolumn{5}{|c|}{ Staphylococcus aureus } \\
\hline FILHO & 2013 & $\begin{array}{c}\text { HSCMV } \\
\text { Vitória - ES }\end{array}$ & $30 / 585$ & 5,1 \\
\hline KORB & 2013 & Fazendo Rio Grande - PR & $7 / 265$ & 2,65 \\
\hline MARTINI & 2011 & Santa Maria - RS & $148 / 6.190$ & 2,4 \\
\hline HORNER & 2008 & $\begin{array}{c}\text { HUSM } \\
\text { Santa Maria - RS }\end{array}$ & $1 / 17$ & 5,8 \\
\hline COELHO & 2008 & $\begin{array}{c}\text { AMI } \\
\text { Tubarão - SC }\end{array}$ & $4 / 11$ & 36,36 \\
\hline DALLACORTE & 2007 & $\begin{array}{l}\text { UPHSL (PUCRS) } \\
\text { Ipiranga - RS }\end{array}$ & $1 / 32$ & 3,1 \\
\hline MÉDIA & - & - & - & 9,2 \\
\hline \multicolumn{5}{|c|}{ Staphylococcus saprophyticus } \\
\hline FILHO & 2013 & $\begin{array}{c}\text { HSCMV } \\
\text { Vitória - ES }\end{array}$ & $30 / 585$ & 5,1 \\
\hline MARTINI & 2011 & Santa Maria - RS & $223 / 6.190$ & 3,6 \\
\hline HORNER & 2008 & $\begin{array}{c}\text { HUSM } \\
\text { Santa Maria - RS }\end{array}$ & $1 / 17$ & 5,8 \\
\hline MÉDIA & - & - & - & 4,8 \\
\hline \multicolumn{5}{|c|}{ Staphylococcus agalactiae } \\
\hline MARTINI & 2011 & Santa Maria - RS & $93 / 6.190$ & 1,5 \\
\hline HORNER & 2008 & $\begin{array}{c}\text { Comunidade } \\
\text { Santa Maria - RS }\end{array}$ & $2 / 10$ & 20 \\
\hline DALLACORTE & 2007 & $\begin{array}{l}\text { UPHSL (PUCRS) } \\
\text { Ipiranga - RS }\end{array}$ & $1 / 32$ & 3,1 \\
\hline MÉDIA & - & - & - & 8,2 \\
\hline
\end{tabular}

$\mathrm{N}$ - Total de bactérias encontras $\mathrm{T}$ - total de uroculturas positivas no estudo. Fonte: Autores.

Os resultados demonstraram com unanimidade que as resistências em Infecções no Trato Urinário apresentaram como principal agente etiológico a Escherichia coli, tendo um percentual variante de no mínimo 38,1\% e máximo de 91\% obtendo uma média aritmética de 57,5\% das infecções constatadas nos estudos descritos. Com base nos mesmos estudos abaixo estão representados na Figura 1 os principais agentes etiológicos responsáveis por causar ITU. 
Figura 1: Média Aritmética aproximada da porcentagem dos principais agentes etiológicos responsáveis por causar Infecção no Trato Urinário, obtidos através da análise de dados dos estudos anteriores citados.

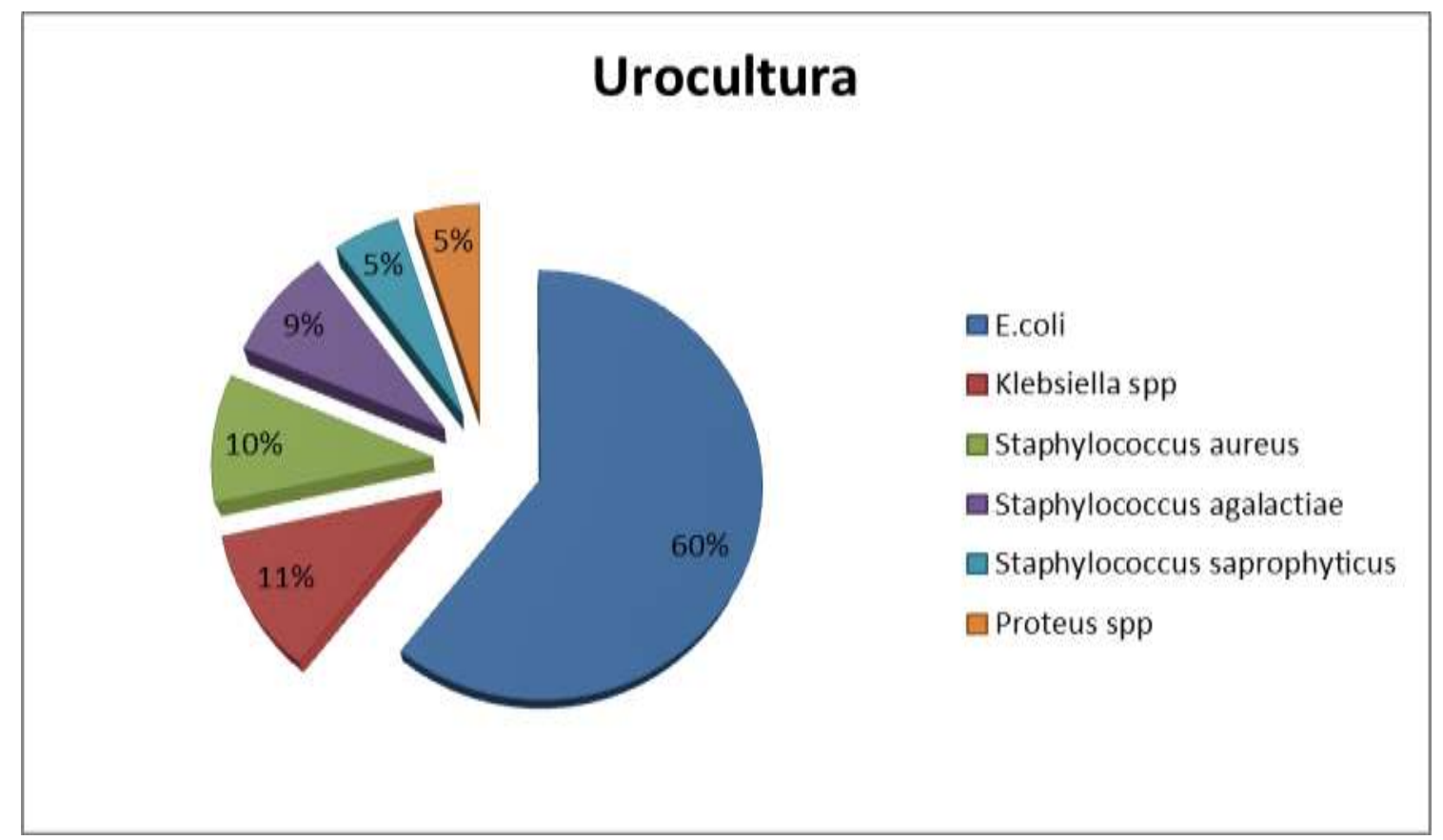

Fonte: Autores.

Os agentes etiológicos da ITU são em sua maioria procedentes da microbiota intestinal, são bacilos gram-negativos da família Enterobacteriaceae, bactérias anaeróbias facultativas que podem ser cultivas em ágar MacConkey, ágar sangue ou ágar EMB, dispõe de requisitos nutricionais simples, fermentam a glicose com produção de ácidos e reduzem o nitrato ao nitrito e não formam esporos (Santana, 2012).

Como observado na Figura 1 a E.coli tem sido relatada como principal enterobactéria responsável por causar ITU durante anos sendo frequentemente relacionadas às Cistites, Uretrites e Pielonefrites, essa bactéria possui adesinas e exotoxinas que permite a sua colonização da uretra, ascendendo até a bexiga permitindo assim como a sua migração até os rins. A família Enterobacteriaceae possui 32 gêneros e 130 espécies, classificadas de acordo as propriedades bioquímicas, estrutura antigênica, hibridização e no sequenciamento dos ácidos nucléicos (Santana, 2012).

De acordo aos estudos originais analisados entre 2007 e 2013 a Tabela 2 apresenta o percentual de resistência bacteriana da E.coli aos antibióticos cujo os dados foram obtidos por meio de antibiogramas afim de se obter uma indicação de antibioticoterapia. 
Tabela 2: Resultados das resistências bacteriana analisadas em estudos originais publicados entre 2007 e 2013.

\begin{tabular}{|c|c|c|c|c|}
\hline \multicolumn{5}{|c|}{ ANTIBIOGRAMA/ E.coli } \\
\hline Estudo & Ano & Local & $\mathbf{N} / \mathbf{T}$ & $\%$ \\
\hline \multicolumn{5}{|c|}{ Ampicilina } \\
\hline FILHO, et al & 2013 & $\begin{array}{c}\text { HSCMV } \\
\text { Vitória - ES }\end{array}$ & $180 / 409$ & 44 \\
\hline KORB, et al & 2013 & Fazendo Rio Grande - PR & $116 / 240$ & 77 \\
\hline SANTANA, et al & 2012 & $\begin{array}{c}\text { Laboratório privado } \\
\text { São Luís - MA }\end{array}$ & $173 / 258$ & 67 \\
\hline DALLACORTE, et al & 2007 & $\begin{array}{c}\text { UPHSL (PUCRS) } \\
\text { Ipiranga - RS } \\
\end{array}$ & $11 / 20$ & 55 \\
\hline MÉDIA & - & - & - & 61 \\
\hline \multicolumn{5}{|c|}{ Fluorquinolonas = norfloxacina e ciprofloxacina } \\
\hline FILHO, et al & 2013 & $\begin{array}{c}\text { HSCMV } \\
\text { Vitória - ES }\end{array}$ & $111 / 409$ & 27,1 \\
\hline KORB, et al & 2013 & Fazendo Rio Grande - PR & $45 / 240$ & 29 \\
\hline SANTANA, et al & 2012 & $\begin{array}{l}\text { Laboratório privado } \\
\text { São Luís - MA }\end{array}$ & $178 / 258$ & 69 \\
\hline DALLACORTE, et al & 2007 & $\begin{array}{l}\text { UPHSL (PUCRS) } \\
\text { Ipiranga - RS }\end{array}$ & $7 / 20$ & 35 \\
\hline MÉDIA & - & - & - & 40 \\
\hline \multicolumn{5}{|c|}{ Nitrofurantoína } \\
\hline FILHO, et al & 2013 & $\begin{array}{c}\text { HSCMV } \\
\text { Vitória - ES }\end{array}$ & $26 / 409$ & 6,4 \\
\hline KORB, et al & 2013 & Fazendo Rio Grande - PR & $19 / 240$ & 12 \\
\hline SANTANA, et al & 2012 & $\begin{array}{l}\text { Laboratório privado } \\
\text { São Luís - MA }\end{array}$ & $168 / 258$ & 65 \\
\hline DALLACORTE, et al & 2007 & $\begin{array}{c}\text { UPHSL (PUCRS) } \\
\text { Ipiranga - RS } \\
\end{array}$ & $5 / 20$ & 25 \\
\hline MÉDIA & - & - & - & 27,1 \\
\hline \multicolumn{5}{|c|}{ Sulfametaxazol+Trimetoprim } \\
\hline FILHO, et al & 2013 & $\begin{array}{c}\text { HSCMV } \\
\text { Vitória - ES }\end{array}$ & $135 / 409$ & 33,3 \\
\hline KORB, et al & 2013 & Fazendo Rio Grande - PR & $8 / 240$ & 5 \\
\hline SANTANA, et al & 2012 & $\begin{array}{l}\text { Laboratório privado } \\
\text { São Luís - MA }\end{array}$ & $178 / 258$ & 69 \\
\hline DALLACORTE, et al & 2007 & $\begin{array}{c}\text { UPHSL (PUCRS) } \\
\text { Ipiranga - RS } \\
\end{array}$ & $8 / 20$ & 40 \\
\hline MÉDIA & - & - & - & 37 \\
\hline \multicolumn{5}{|c|}{ Ácido nalidíxico } \\
\hline FILHO, et al & 2013 & $\begin{array}{c}\text { HSCMV } \\
\text { Vitória - ES }\end{array}$ & $78 / 409$ & 19,1 \\
\hline KORB, et al & 2013 & Fazendo Rio Grande - PR & $30 / 240$ & 20 \\
\hline SANTANA, et al & 2012 & $\begin{array}{c}\text { Laboratório privado } \\
\text { São Luís - MA }\end{array}$ & $183 / 258$ & 71 \\
\hline MÉDIA & - & - & - & 37 \\
\hline
\end{tabular}

$\mathrm{N}$ - Total de bactérias encontras $\mathrm{T}$ - total de uroculturas positivas no estudo. Fonte: Autores.

De acordo aos antibiogramas realizados observou-se a partir da figura 3 que para as cepas de E. coli o principal antimicrobiono listado como resistente foi a ampicilina tendo um percentual variante de no mínimo 44\% e máximo de $77 \%$ apresentando uma média aritmética de $61 \%$.

Os genes responsáveis para a resistência aos antimicrobianos bectalactâmicos como a ampicilina citada anteriormente encontra-se difundido no ambiente, sendo principalmente constatado pelo uso intensivo na saúde humana assim como de resíduos provenientes de alimentos de origem animal. A Organização Mundial de Saúde recomenda prudência na prescrição de antibiótico nos casos de emergência sem antibiograma quando este apresentar índices de resistência de 20\% (Korb, 2013). 
Para Dallacorte e Benjamin (2007) "As elevadas taxas de resistência à ampicilina e a sulfametoxazol + trimetoprima reforçam os conhecimentos prévios a respeito do uso empírico dessas drogas".

A ineficácia da ampicilina e a trimetoprima em ITU em comunidades e em pacientes hospitalizados é relatado em diversos estudos, a resistência pode ser explicada pela existência de plasmídeos transmissível em E.coli que codificam a resistência de ambos (Santana, 2012).

"O uso indiscriminado de antibióticos, com ou sem receitas médica, é responsável pelos níveis crescentes de resistência bacteriana, mesmo no contexto de atendimento ambulatorial. No ambiente hospitalar este pressuposto também é verdadeiro e reforça a necessidade do uso racional dos antimicrobianos" (Dallacorte et al., 2007).

Diante dos estudos revisados observou-se ainda que alguns grupos são mais suscetíveis a ITU, dentre eles encontramse as gestantes e os idosos. Durante o período gestacional o aparecimento de ITU é justificado pela diminuição do peristaltismo e dilatação da uretra por ação hormonal tendo também relação com a pressão que o útero exerce sobre os ureteres assim como a supressão do sistema imunológico para manutenção do feto. Em pacientes idosos a ITU ocorre frequentemente mediante alta prevalência de incontinência urinária, uso de fraudas, histórico de antibióticos, vida sexual ativa, deficiência estrogênica pósmenopausa em mulheres e hipertrofia prostática nos homens (Dallacorte et al., 2007; Santana et al., 2012).

\section{Conclusão}

O estudo comprovou que o agente etiológico de maior prevalência na ITU é a Escherichia coli, responsável por $57,5 \%$ das infecções e também é a bactéria que apresentou maior resistência ao antibiótico Ampicilina em $61 \%$ dos antibiogramas realizados.

O sumário de urina se apresentou como importante ferramenta na triagem diagnóstica da Infecção do Trato Urinário seja na Cistite, Uretrite ou Pielonefrite. De acordo com os artigos originais indexados o sumário de urina é indicativo para ITU quando denota na análise química o nitrito positivo podendo acompanhar a presença de leucócitos e/ou sangue e na análise sedimestocopica a presença de numerosas bactérias podendo correlacionar-se a piúria e/ou hematúria, observa-se ainda que urinas de pacientes com ITU apresenta um aspecto turvo, no entanto os estudos apontaram que a urocultura não pode ser excluída mesmo quando o sumário de urina não for indicativo de ITU, uma vez que foram obtidos uroculturas positivas provenientes de sumários de urina normais.

Observou-se ainda um aumento no crescimento de resistências aos antimicrobianos tanto de pacientes hospitalizados quanto externos, chamando atenção para algumas evidências como a prescrição inadequada de antibióticos pela classe médica. Mediante a resistência que os uropatógenos vêm desenvolvendo torna-se necessário e indispensável à realização da urocultura com antibiograma para determinar a bactéria responsável pelo processo infeccioso e listar os antibióticos mais adequado para o mesmo.

É crescente o número de pacientes que apresentam resistência bacteriana na utilização de antibióticos pelo uso indiscriminado ou indevido do mesmo por tanto faz se necessário à realização de novos estudos a fim de se apresentar novos dados estáticos com a finalidade de conscientizar a antibioticoterapia na cistite, uretrite e pielonefrite após o resultado do exame de urocultura com antibiograma o qual se espera diminuir os índices de resistências aos antimicrobianos.

\section{Agradecimentos}

Agradecemos a Deus que é a inteligência suprema, a causa primária de todas as coisas pelo dom da vida, discernimento, ciência, fortaleza e sabedoria. 


\section{Referências}

Alves, M. Lima. Análises Laboratoriais. DCL. 19 à 74;

Bulka, L. C. \& Furlani, M. C. L. (2016). As complicações da infecção urinaria em gestantes. Revista Fait. http://fait.revista.inf.br/imagens_arqui vos/arquivos_destaque/Ty0lcaKZ6aB1ZPG_2015-2-3-14-30-55.pdf.

Bignardi, F. A. C. (20011). Reflexões sobre a pesquisa qualitativa e quantitativa: maneiras complementares de aprender a realidade. http: http:www.comitepaz.org.br/download/PESQUISA\%20QUALITATIVA.pdf.

Coelho, F., Sakae, T. M. \& Rojas, P. F. B. (2005). Prevalência de Infecções do trato urinário e bacteriuria em gestantes da clínica ginecológica do ambulatório materno infantil de Tubarão - SC. ACM arq. catarin. Med. 37(3), 44-51. graf. http://bases.bireme.br/cgibin/wxislind.exe/iah/online/?IsisScript=iah/iah.xis\&src=google\&base=LILACS\&lang=p\&nextAction=lnk\&exprSearch=503674\&indexSearch=ID.

Corrêa, E. F. \& Montalvão, E. Infecção do Trato Urinário em Geriatria. Estudos, Goiânia, 37, 625-635, http: seer.ucg.br/index.php/estudos/ article/download/1831/1135.

Dallacrote, R. R., Roberta R., Rodolgo H. S. \& Winston, W. B. Perfil das infecções do trato urinário da Unidade de Geriatria do Hospital São Lucas da PUCRS. Scientia Medica, 17, 197-204. http://revistaeletronicas.pucrs.br/ojs/index.php/scientiamedica/article/2750.

Filho, A. C. et al. Estudo do perfil de resistência antimicrobiana das infecções urinárias em mulheres atendidas em hospital terciário. Rev. Bras Cli Med.; 11(2). http://files.bvs.br/upload/S/1679-1010/2013/v11n2/a3559.pdf.

Filho, J. S. R. et al. Infecção do trato Urinário: Urinary tract infection. Medicina 43(2): 118-25. http://revista.fmrp.usp.br/2010/vol43n2/Simp3_Infe c\%E7\%E3o\%20do\%20trato\%20urin\%E1rio.pdf.

Galvão, T. F., Andrade, T. S. \& Harrad, P. D. Principais itens para relatar Revisões sistemáticas e Meta-análises: A recomendação PRISMA. Epidemiol. Serv. Saúde. 24(2): 335-342. http://www.scielosp.org/scielo.php?script=sci_arttext\&pid=S2237-96222015000200335\&lng=en. http://dx.doi.org/10.5123/S167949742015000200017.

Guerra, G. V. Q. L. et al. Exame simples de urina no diagnóstico de infecção urinária em gestantes de alto risco. Rev. Bras. Ginecol. Obstet. 34, 488-493. http://www.scielo.br/scielo.php?script=sci_arttext\&pid=S0100-72032012001100002\&lng=en\&nrm=iso>. https://doi.org/10.1590/S0100-720320120011000 0212

Lehninger, A. L. \& Nelson D.L.C. M. M. Lehninger Princípios deBioquímica. (4a ed.), Sarvier, (22):639-679;

Guidoni, E. B. M. \& Toporobski, J. Infecção Urinária na adolescência. Jornal de Pediatria. 77, http://www.jped.com.br/conteudo/01-77-S165/port.pdf.

Horner, R. et al. Comparação de métodos de triagem para detecção de bacteriúria em amostras do bairro Maringá e do hospital universitário de Santa Maria. Saúde, Santa Maria, 34a, 16-21. https://periodicos.ufsm.br/revistasaude/article/view/6491/3944.

Korb, A., Nazareno, E. R., Mendonça, F. A. \& Dalsenter, P. R. Perfil de resistência da bactéria Escherichia coli em infecções do trato urinário em pacientes ambulatoriais. Revista de Biologia e Ciências da Terra, 13. http://joaootavio.com.br/bioterra/workspace/uploads/artigos/666-2770-1-pb-53df8cea94fa.pdf.

Lopes, H. V. \& Tavares, W. Diagnóstico das infecções do trato urinário. Rev. Assoc. Med. Bras. 51, 306-308. http://www.scielo.br/scielo.php?script =sci_arttext\&pid=S0104-42302005000600008\&lng=en\&nrm=iso. https://doi.org/10.1590/S0104-42302005000600008.

Martini, R. et al. Caracterização de culturas de urina realizadas no laboratório de análises clínicas do hospital universitário de Santa Maria. Saúde, Santa Maria, $R S$, no período de 2007 a 2010. 37. https://periodicos.ufsm.br/revistasaude/article/view/3565.

Nerbas, F. B. et al. Técnicas de enfermagem têm uma prevalência maior de sintomas e infecções do trato urinário do que outras ocupações em unidades de diálise. Articles • Braz. J. Nephrol. https://doi.org/10.1590/2175- 8239-JBN-2020-0248

Santana, T. C. F. S. et al. Perfil de Resistência de Escherichia coli e Klevsiella spp Isoladas de Urocultura de Comunidade do Município de São Luís-Ma no período de 2005-2008. 41 (3): 295-303. https://www.revistas.ufg.br/iptsp/article/viewFile/20754/12177.

Strasinger, S. K. \& Lorenzo, M. S. D. Urinálise e fluidos corporais. (5a ed.), Editora LMP (Livraria Médica Paulista), 2009 (1-07): 01-153;

Teixeira, E. B. A Análise de dados na Pesquisa Ciêntifica. Importância e desafios em estudos organizacionais. http://cursodegestaoelideranca.pa ginas.ufsc.br/file s/2016/03/Artigo-An\%C3\%A1lise-de-dados-na-pesquisa.pdf> 